\title{
A Heterobimetallic Ru(II)-Cu(II) Donor-Acceptor Complex as a Chemodosimetric Ensemble for Selective Cyanide Detection
}

Cheuk-Fai Chow ${ }^{\mathrm{a}}$, Michael H. W. Lam*a ${ }^{\mathrm{a}}$, Wai-Yeung Wong ${ }^{\mathrm{b}}$

${ }^{a}$ Department of Biology \& Chemistry, City University of Hong Kong, 83 Tat Chee Ave., Hong Kong SAR, China

b Department of Chemistry, Hong Kong Baptist University, Waterloo Road, Kowloon Tong, Hong Kong SAR, China

\section{Supporting Information}

Fig. 1 IR spectra of 1 with $\mathrm{KBr}$ pellet. The $v_{\mathrm{C} \equiv N}\left(\mathrm{~cm}^{-1}\right)$ of $\mathbf{1}$ is located at $2055 \mathrm{~cm}^{-1}$.

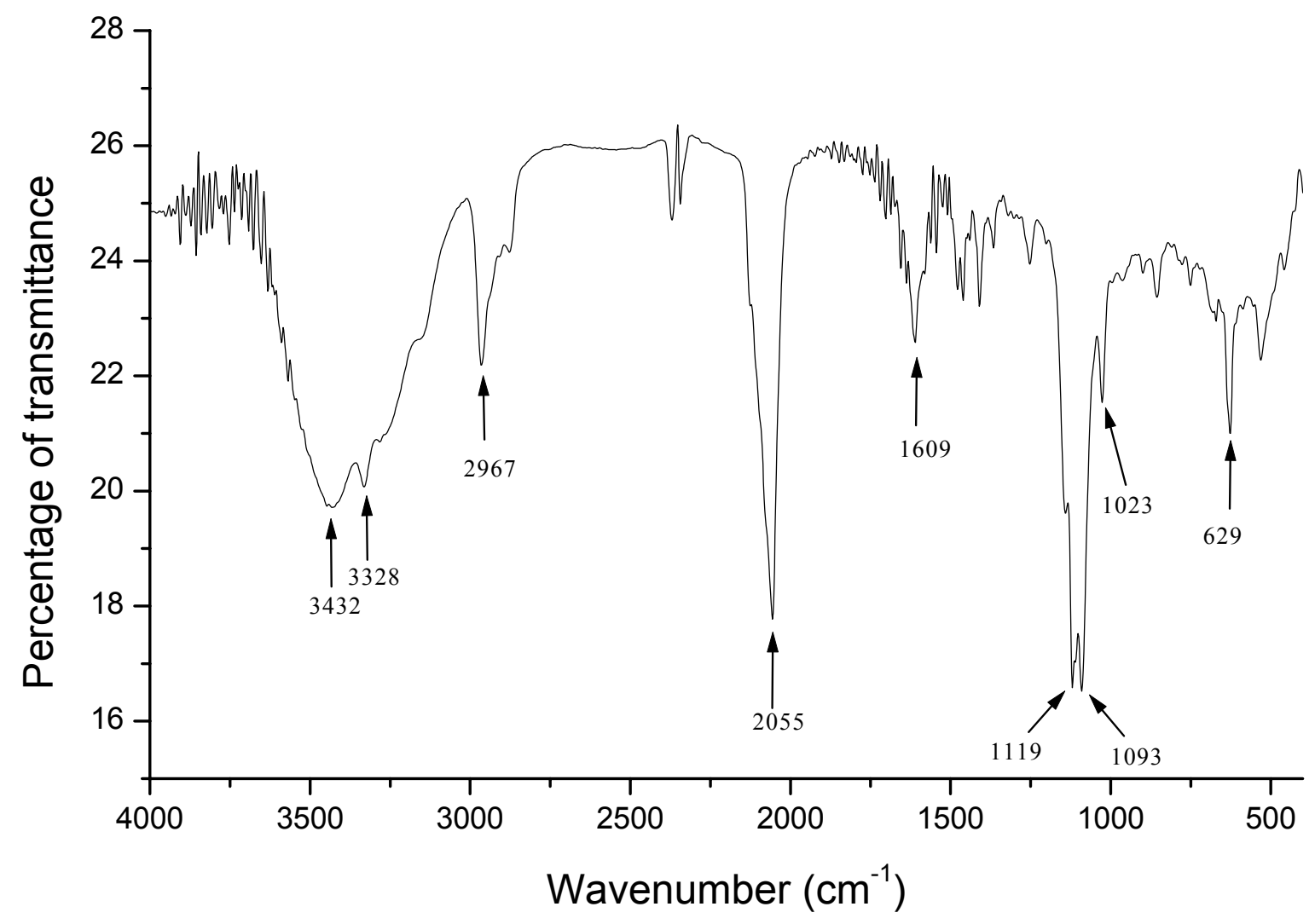


Fig. 2 Solution IR spectrum of $\mathbf{1}$ in methanol.

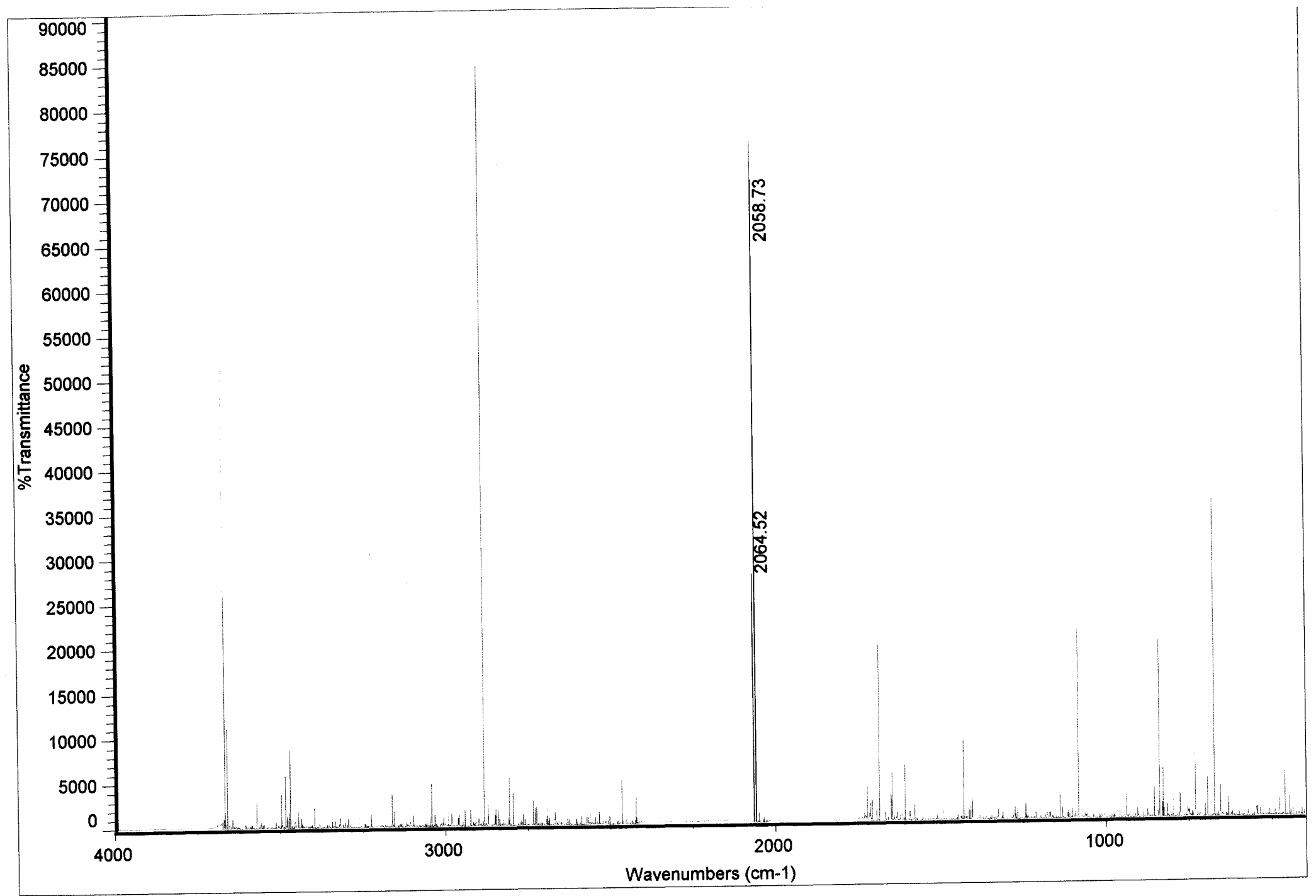


Fig. 3 Isotopic distribution of ESI-MS of $\left\{\mathrm{Ru}^{\mathrm{II}}\left({ }^{\mathrm{t}} \mathrm{Bubpy}\right)(\mathrm{CN})_{4}-\left[\mathrm{Cu}^{\mathrm{II}}(\mathrm{dien})\right]_{2}\right\}^{2+}(\mathbf{1})$ in methanol. The parent ion at $\mathrm{m} / \mathrm{z} 907 \mathrm{corresponds}$ to $\left[\mathrm{M}-\mathrm{ClO}_{4}\right]^{+}$fragment. The simulated isotopic distribution is shown in the inset.

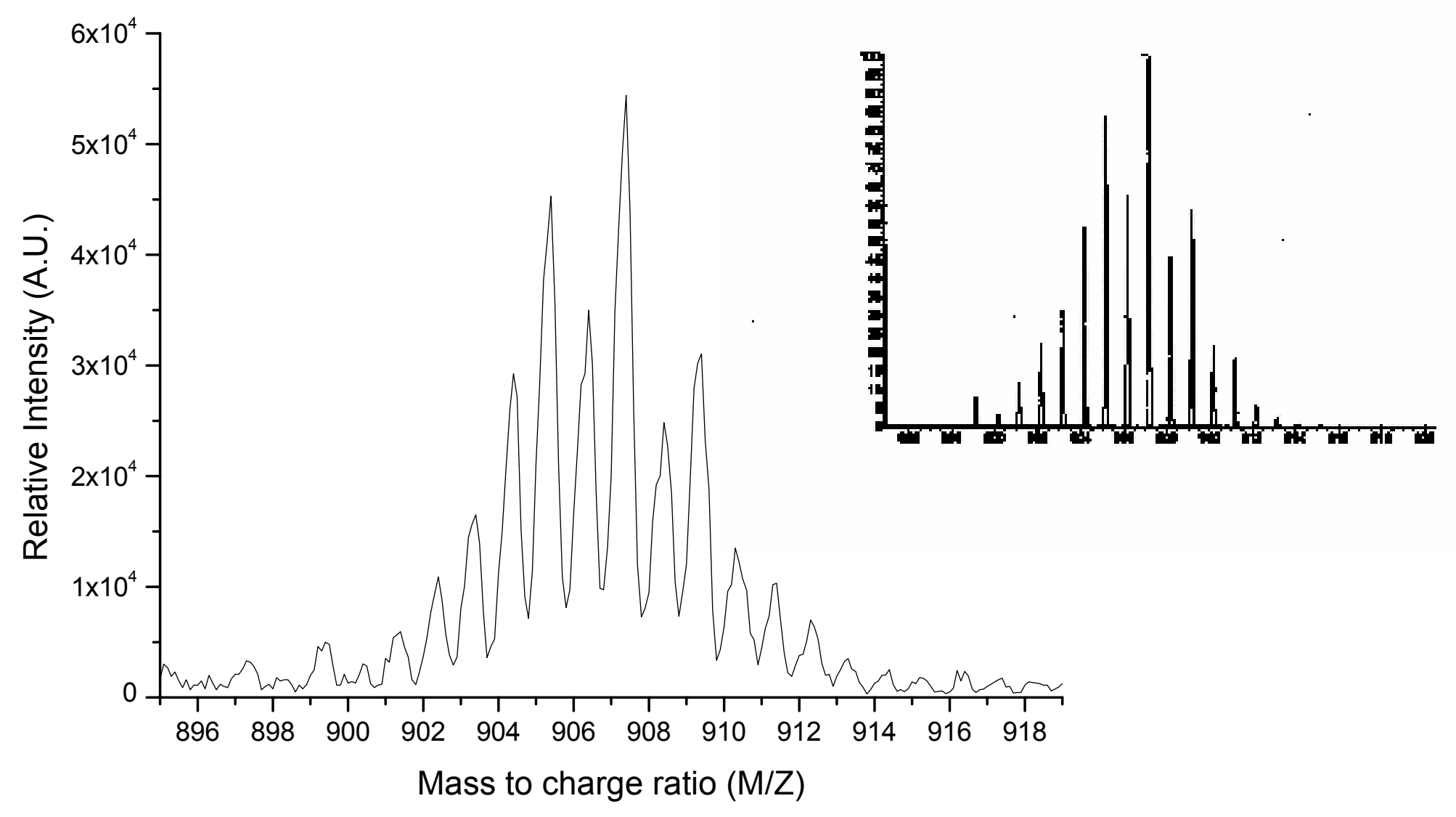


Fig. 4 Binding isotherm of $c i s-\left[\mathrm{Ru}(\mathrm{bpy})_{2}(\mathrm{CN})_{2}\right]\left(1.25 \times 10^{-3} M\right.$ in 1:1 DMF:HEPES $)$ by $[\mathrm{Cu}$ (dien) $]\left(\mathrm{ClO}_{4}\right)_{2}$ monitored by the quenching of the ${ }^{3} \mathrm{MLCT}$ emission of cis-[Ru(bpy $\left.)_{2}(\mathrm{CN})_{2}\right]$ at $634 \mathrm{~nm}$. The binding equilibrium is reached at 1:1 cis-[Ru(bpy $\left.)_{2}(\mathrm{CN})_{2}\right]:[\mathrm{Cu}(\operatorname{dien})]\left(\mathrm{ClO}_{4}\right)_{2}$. Thus, the donor-acceptor adduct, 2 , formed is denoted cis- $\left[\mathrm{Ru}(\mathrm{bpy})_{2}(\mathrm{CN})_{2}\right]-[\mathrm{Cu}(\mathrm{dien})]^{2+}$.

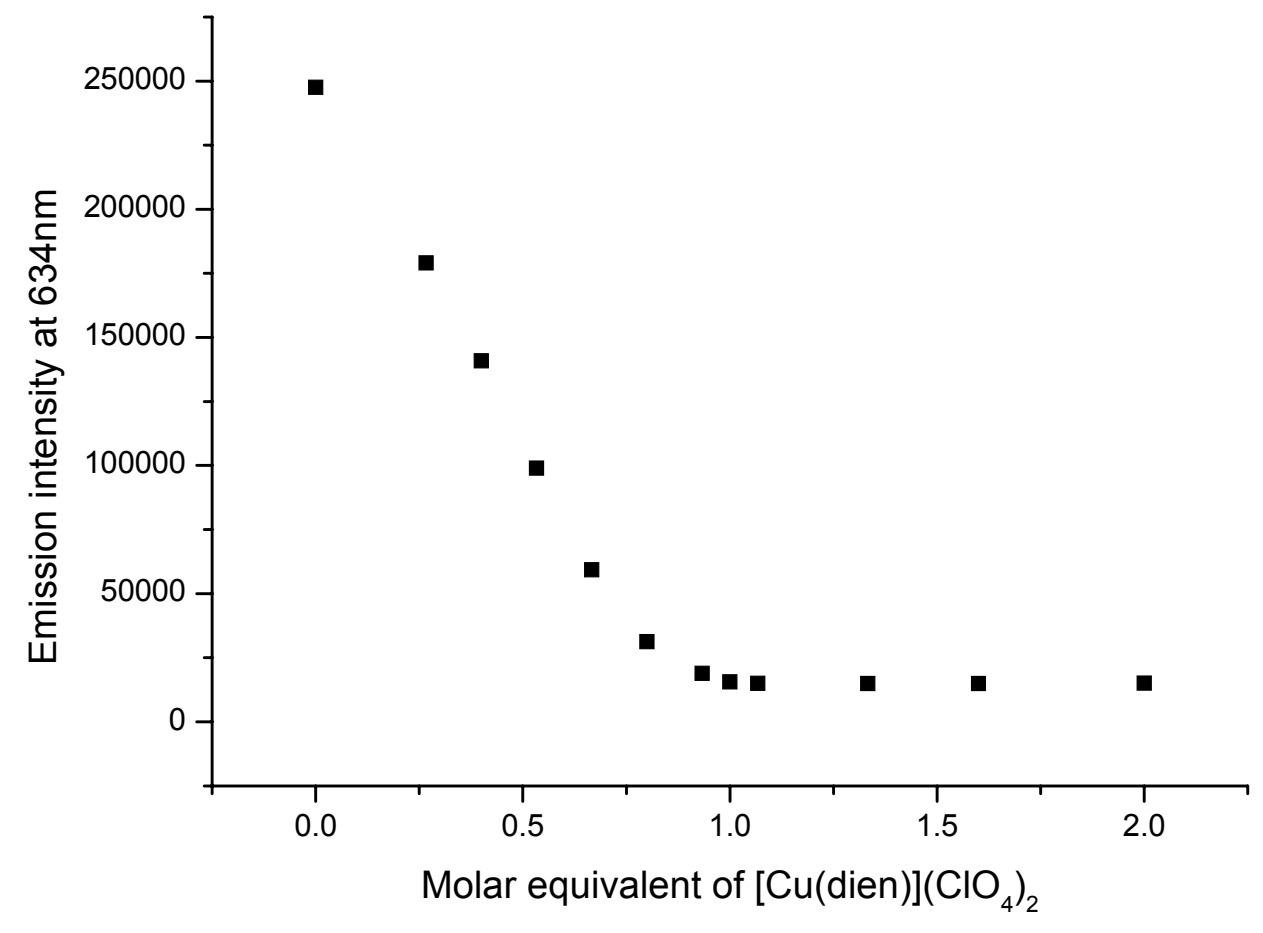


Fig. 5 Spectrofluorimetric titration of $c i s-\left[\mathrm{Ru}(\mathrm{bpy})_{2}(\mathrm{CN})_{2}\right] \quad\left(\begin{array}{lllll}5.0 & \times & 10^{-5} & \mathrm{M}\end{array}\right)$ with $[\mathrm{Cu}($ dien $)]\left(\mathrm{ClO}_{4}\right)_{2}\left(0\right.$ to $\left.2.0 \times 10^{-3} \mathrm{M}\right)$ in aqueous DMF $(1: 1 \mathrm{v} / \mathrm{v})(\mathrm{pH} 7.4)$. The slope and $\mathrm{y}-$ intercept of the best fitted $\mathrm{I}_{\mathrm{O}} /\left(\mathrm{I}-\mathrm{I}_{\mathrm{O}}\right)$ vs. $1 /[\mathrm{Cu}(\text { dien })]^{2+}$ plot are $2.14 \pm 0.052 \times 10^{-3} \mathrm{M}$ and $8.97 \pm$ $0.67 \times 10^{-1}$ respectively. According to Equation (2), the $\Delta \mathrm{G}^{0}$ of formation of the donoracceptor adduct 2 is estimated to be $-14.8 \mathrm{~kJ} \mathrm{~mol}^{-1}$.
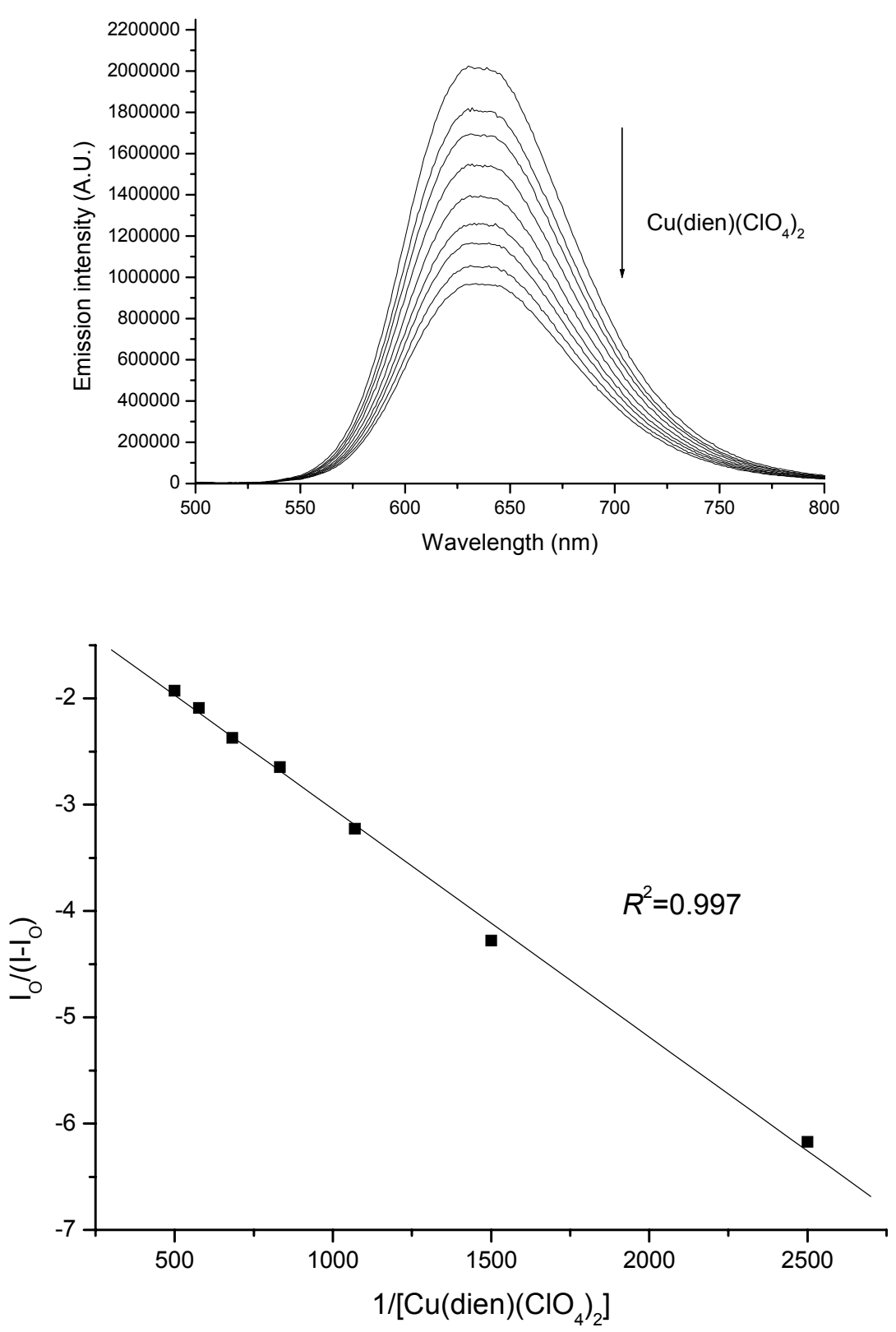
Fig 6 Isotopic distribution of ESI-MS of the m/z 497 peak corresponding to $\left[\mathrm{Ru}\left({ }^{\mathrm{t}} \mathrm{Bubpy}\right)(\mathrm{CN})_{4}+\mathrm{Na}\right]^{-}$obtained from a mixture of 1 and sodium cyanide. The simulated isotopic distribution is shown in the inset.

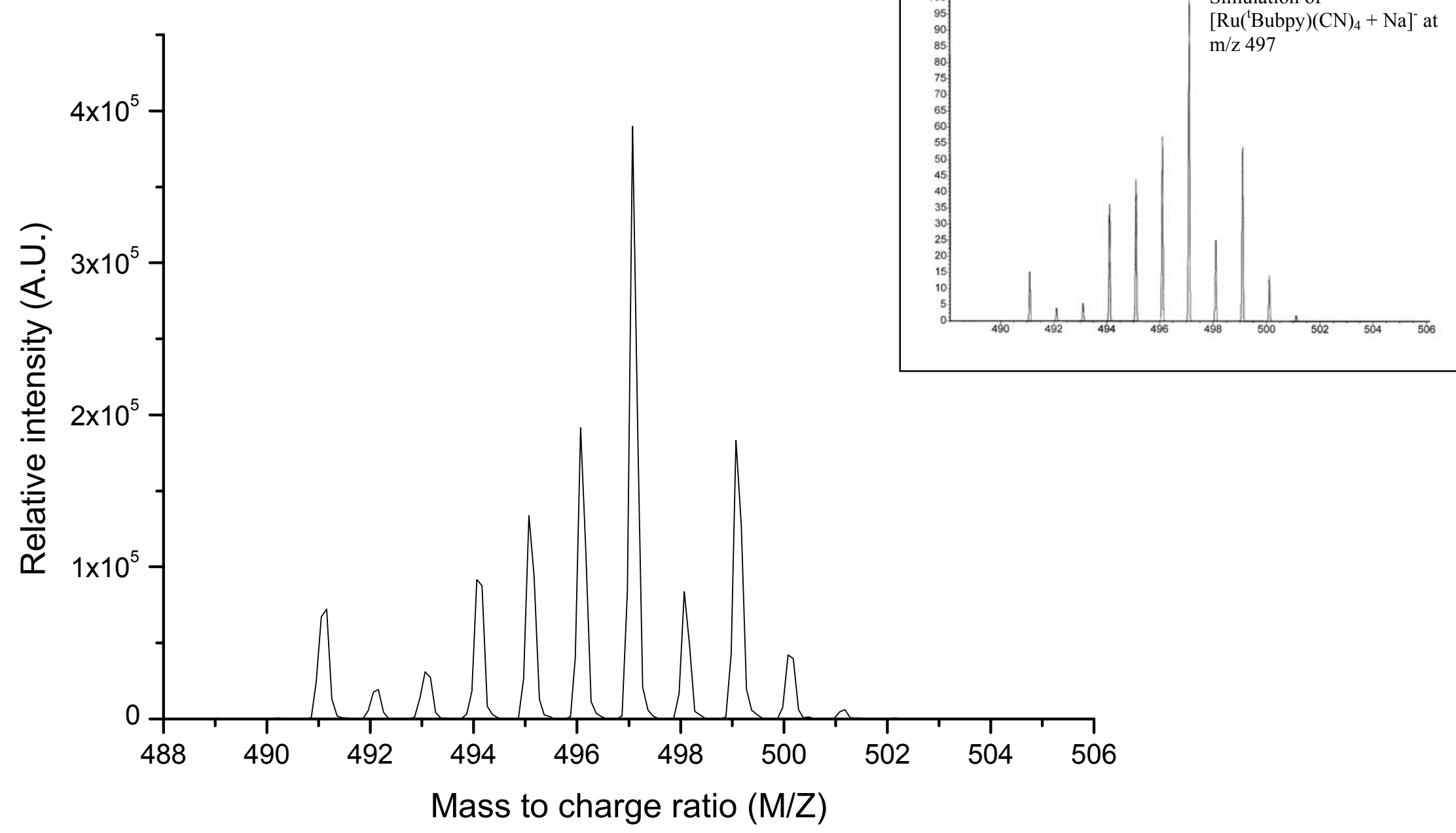


Fig. 7 Job's plot of the luminescent responses of solvated $1(\mathrm{~L}=$ solvent) towards cyanide showing that the maximum response occurs at $1: \mathrm{CN}^{-}$mole ratio of 1:4. This implies that each $\mathrm{Cu}(\mathrm{II})$ center of 1 binds two $\mathrm{CN}^{-}$.
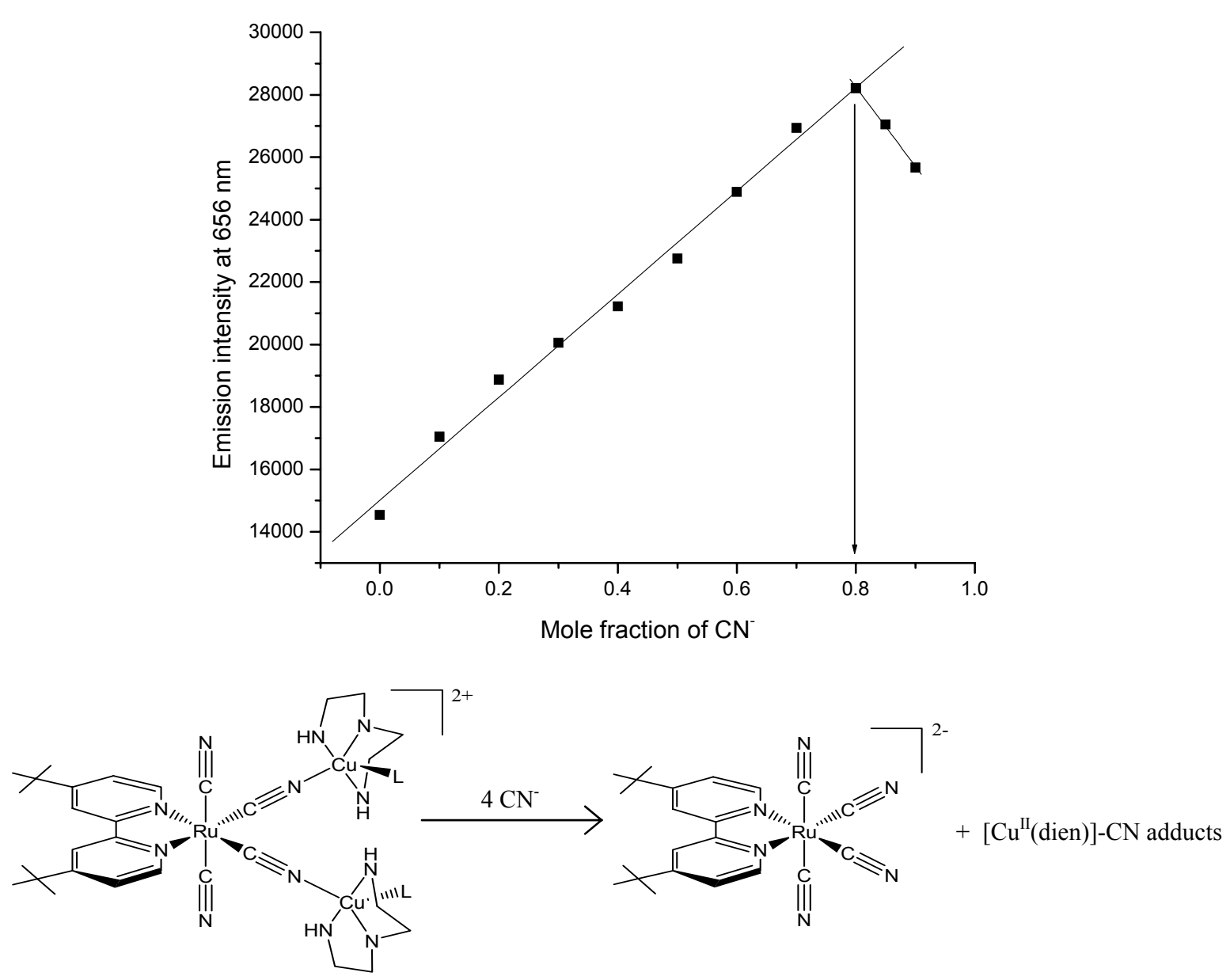
Fig. 8 Fitting of the luminescent responses $\mathrm{I}_{\mathrm{O}} /\left(\mathrm{I}-\mathrm{I}_{\mathrm{O}}\right)$ of $1\left(1.40 \times 10^{-4} \mathrm{M}\right)$ at $656 \mathrm{~nm}$ towards $\mathrm{CN}^{-}$according to the $1: 2$ binding model. The slope and $y$-intercept of the best fitted $\mathrm{I}_{\mathrm{O}} /\left(\mathrm{I}-\mathrm{I}_{\mathrm{O}}\right)$ vs. $1 /\left[\mathrm{CN}^{-}\right]^{2}$ plot are $7.94 \pm 0.069 \times 10^{-9} M^{2}$ and $5.87 \pm 0.11 \times 10^{-2}$ respectively. The luminescent responses of $\mathbf{1}$ are shown in the inset.

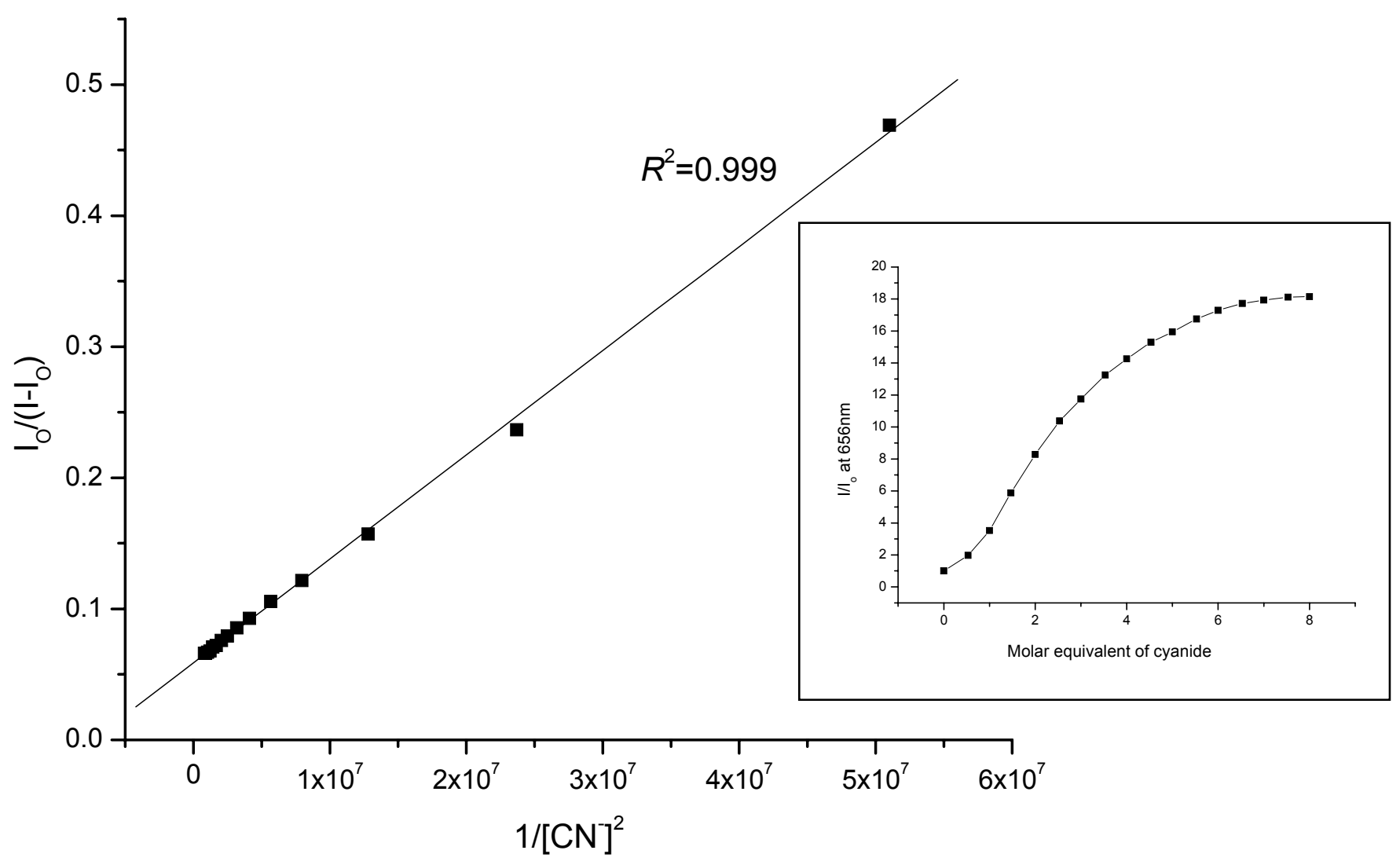


Fig. 9 Summary of UV-vis spectroscopic (top left) and spectrofluorimetric (top right) titrations of 1 (1.40 $\left.\times 10^{-4} \mathrm{M}\right)$ by common anions monitored as a function of the increase in absorbance $\left(\mathrm{A} / \mathrm{A}_{\mathrm{O}}\right.$ at $\left.475 \mathrm{~nm}\right)$ and emission $\left(\mathrm{I} / \mathrm{I}_{\mathrm{O}}\right.$ at $\left.656 \mathrm{~nm}\right)$ respectively. All titrations were carried out in aqueous DMF $(1: 1 \mathrm{v} / \mathrm{v})$ at $\mathrm{pH} 7$ at $298 \mathrm{~K}$.
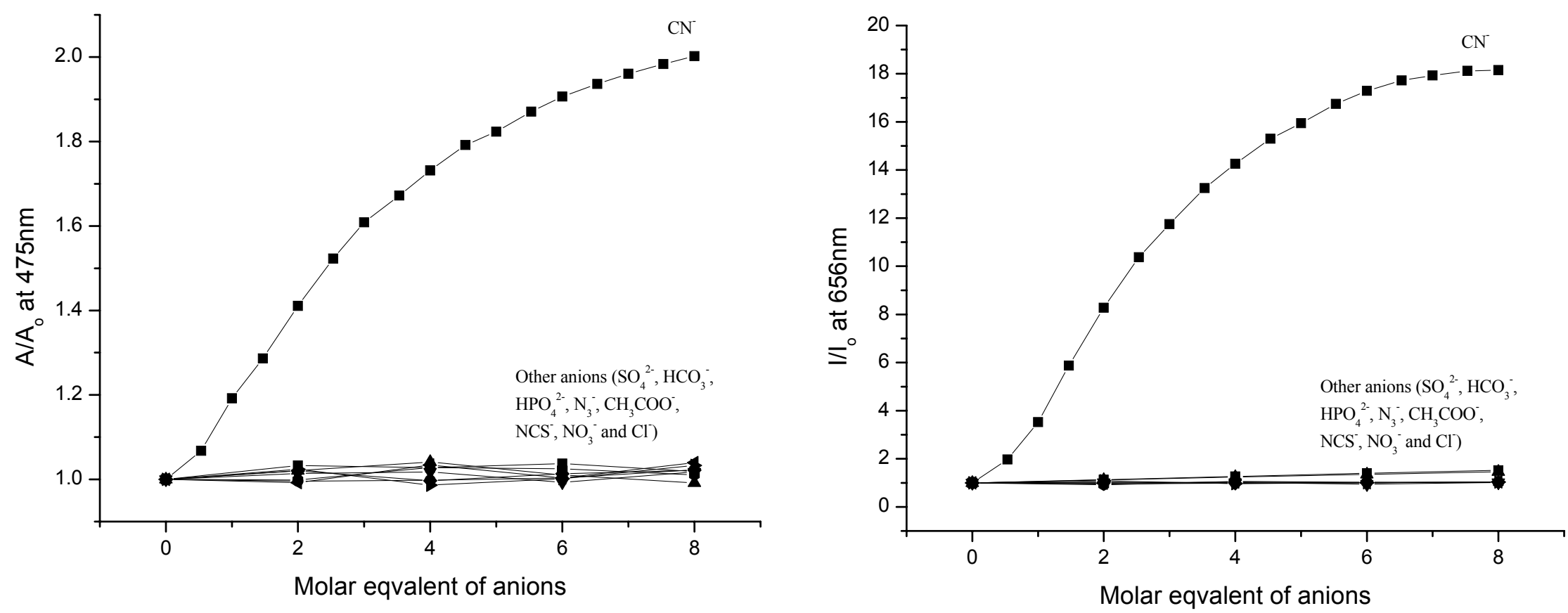